\title{
Response to Dopaminergic Drugs After Fetal Tissue Transplantation. Preliminary Report
}

\author{
L. Alvarez, H. Molina, R. Quiñones, J.L. Muñoz, C. González, J.C. García, I. Ortega, \\ C. Suărez, O. Torres, M. Rachid, L. Bonet, F. Tejeda, M. León and F. Araújo
}

Centro Iberolatinoamericano de Transplante y Regeneración del Sistema Nervioso, Ave. 25 \# 15805, Cubanacán, Playa, Ciudad Habana, Cuba

From 1987 to the present our Cuban Centre has performed more than 30 foetal nigral transplants to the striatum in patients with Parkinson's disease. To study the improvement reported in dopaminergic drug response and the decrease L-Dopa daily dose together with better motor performance $/ 1 /$, the present pharmacological trial was applied to four Parkinsonian patients, who underwent stereotactic implantations of foetal ventral mesencephalon dissociated cells.

Four male patients with idiopathic Parkinson's disease were studied during their hospitalization (approximately one year). They were diagnosed and followed clinically according to the CAPIT recommendations.
Using stereotactic technique we performed computer-assisted CT-guided transplantation of foetal mesencephalic cell suspensions to the right striatum of the four patients.

The clinical evolution was evaluated by a single L-Dopa response test and the apomorphine dose-response curve (using $1 \mathrm{mg}$ to $4 \mathrm{mg}$ ) before, and 30, 60 and 90 days after surgery. Biochemical studies included the measurement of L-Dopa, 3-O-methyl-dopa and catecholamine catabolites in CSF by HPLC pre-operatively and 60 days after the implant. Statistical analyses were performed by Wilcoxon paired rank test and lineal correlation methods.

Changes in the rates of the response (increase of "on" phase duration and decrease in "on"
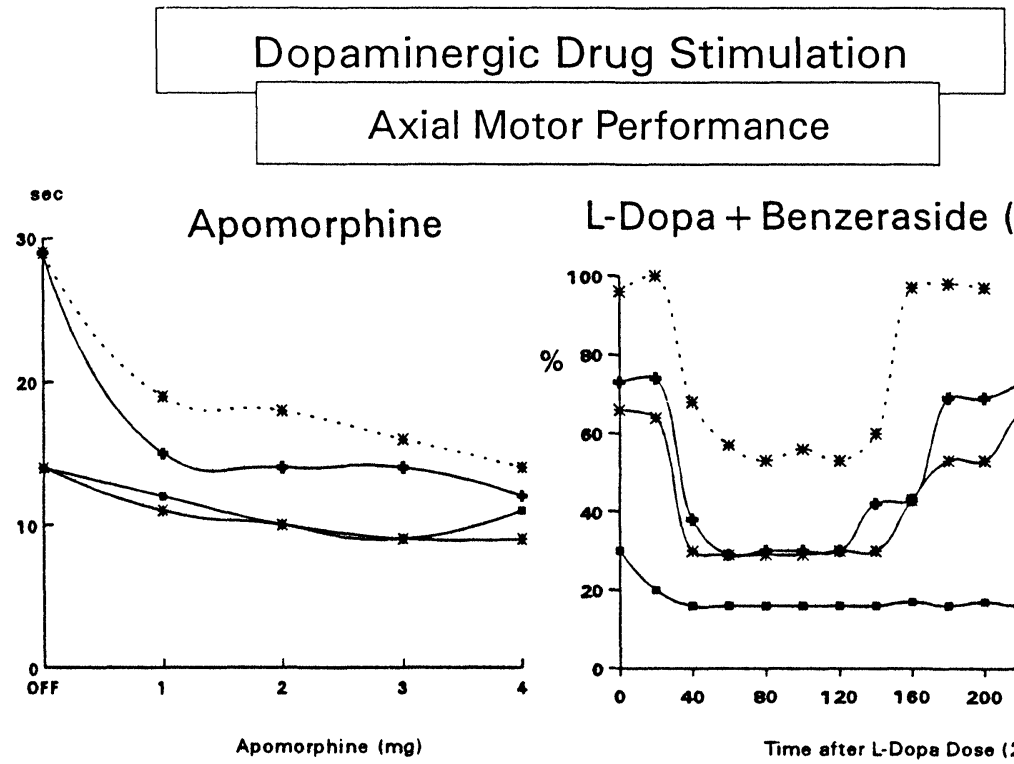

L-Dopa + Benzeraside (4:1)

* Pre +30 days $* 60$ days $\rightarrow 90$ days 
latency) were observed in the single dose LDopa test, together with a decreased magnitude of the response, at 90 days after implants $(\mathrm{P}<0.05)$. All patients showed bilateral improvement but asymmetrically, better on the left side. Also reduction of dyskinesias was observed. These effects were similar to the apomorphine dose-response test; in fact, this is closely dosecorrelated in patient number four (CR:0.68). The most significant improvement was an improved motor performance during baseline ("off" phase).

CSF levels of DOPAC were increased 60 days after nigral implants and the levels of HVA in the CSF were higher in response to the same dose of L-Dopa (250 mg madopar).

In summary, different patterns of response to dopaminergic drugs after the implant, characterized by shorter latency, a larger "on" phase, reduced magnitude of response, lack of signifi- cant dyskinesias, better motor performance in basal "off", and higher increments of HVA in CSF in response to L-Dopa, developed in our patients, similarly to Parkinsonian patients with short-term L-Dopa therapy.

These data support the hypothesis that transplants induce the restoration of dopaminergic pathways.

\section{REFERENCES}

1. Molina $\mathrm{H}$ et al. Transplantation of human fetal mesencephalic tissue in caudate nucleus as treatment for Parkinson's Disease: the Cuban experience in intracerebral transplantation in movement disorders. Lindvall $\mathrm{O}$, Björklund $\mathrm{A}$, Widner $\mathrm{H}$, eds. Elsevier Science Publishers B.U. 1991.

2. Langston WJ et al. Core assessment program for intracerebral transplantation (CAPIT). Movement Disorders 1992; 7: 2-13. 

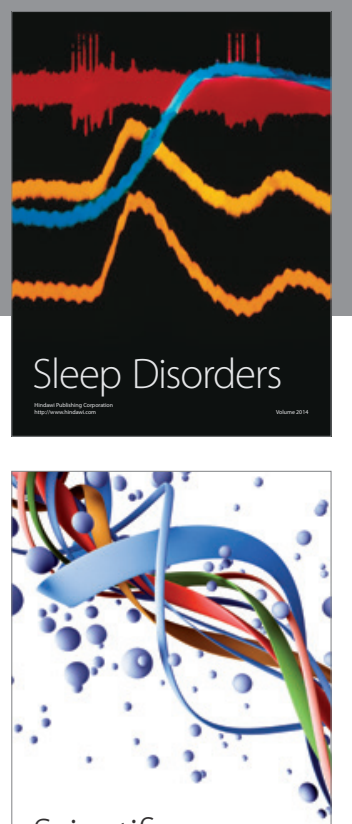

Scientifica
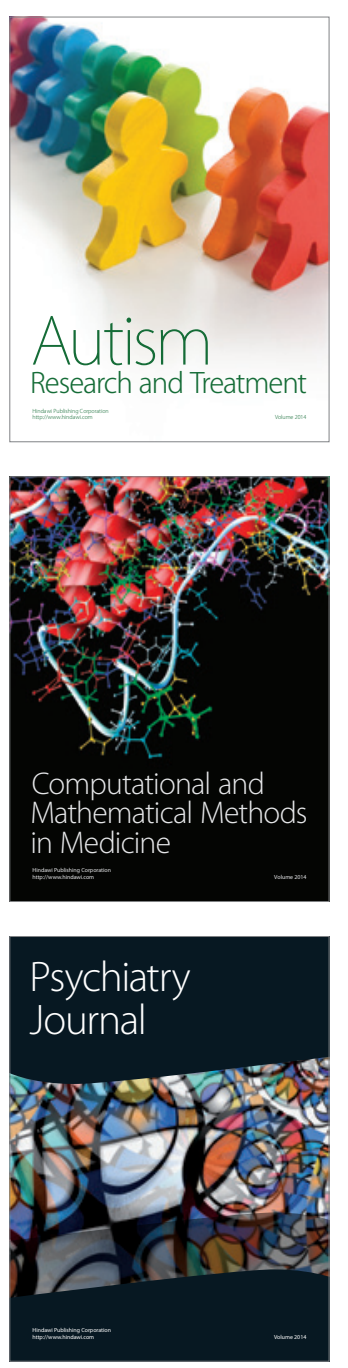
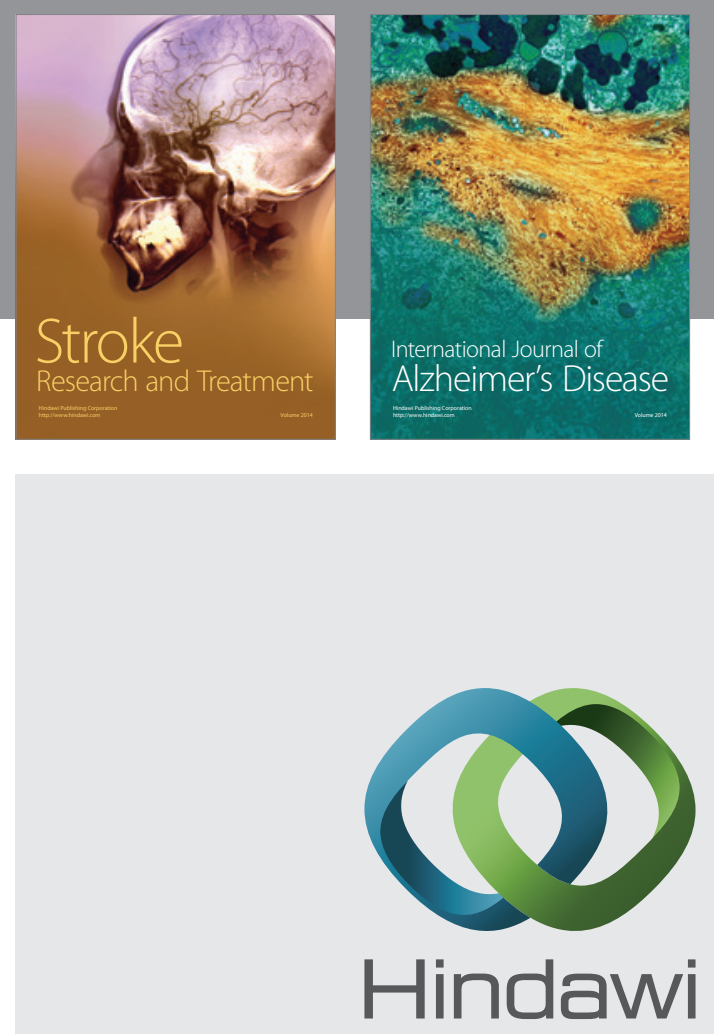

Submit your manuscripts at

http://www.hindawi.com
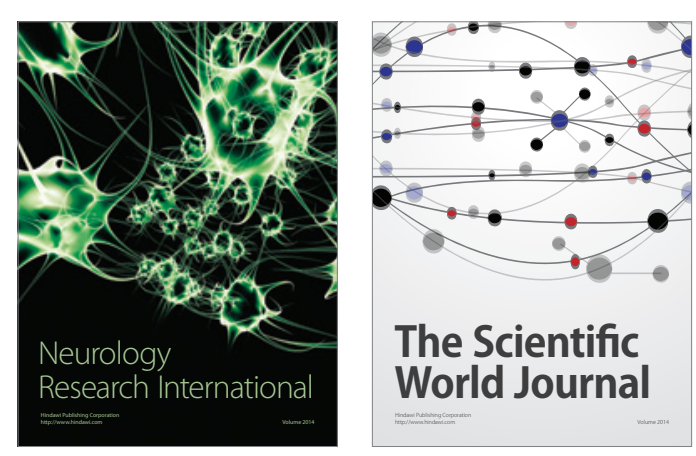

The Scientific World Journal

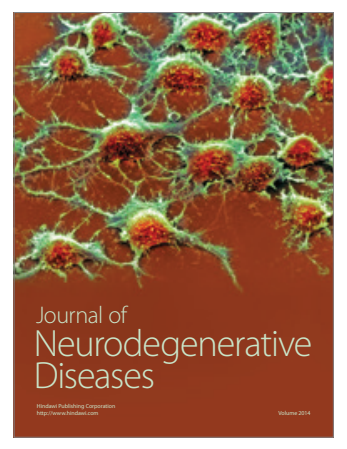

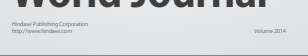

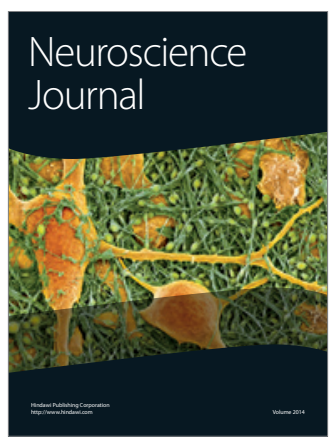

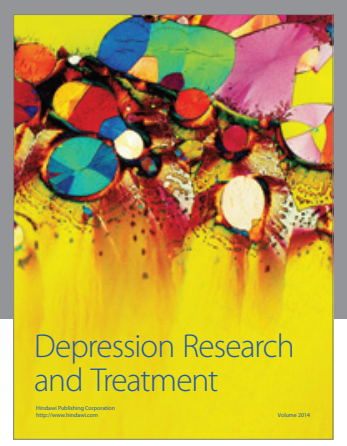
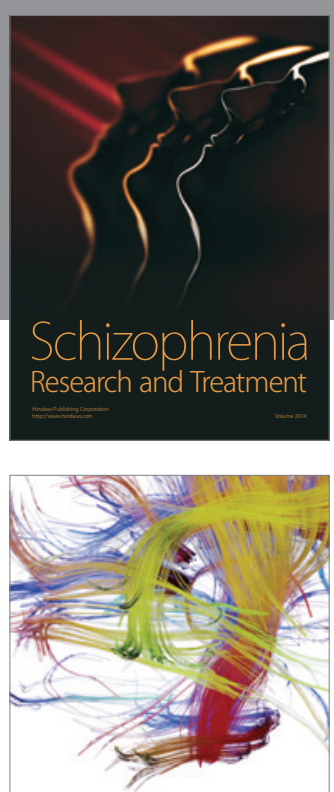

Brain Science

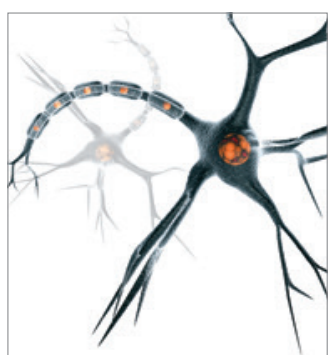

Neural Plasticity
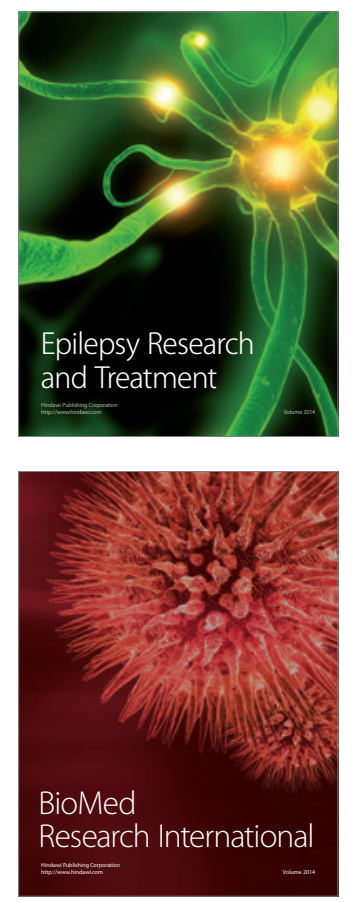

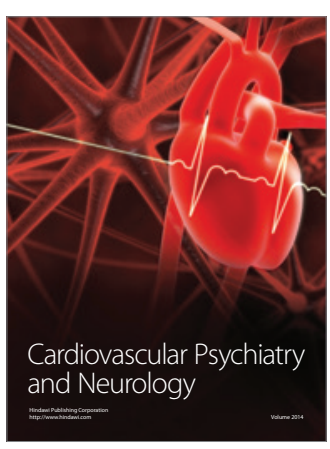

Parkinson's

Disease
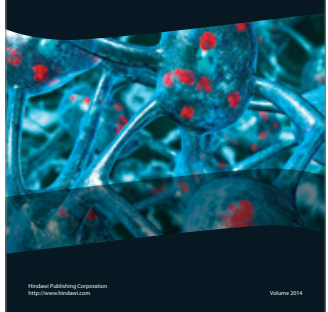